\title{
TRANSFORMATION IN EDUCATION AND IMPORTANCE OF E-LEARNING POST COVID-19
}

\author{
DEEPAK CHAKRAVARTY ${ }^{1} \&$ MAHIMA GUPTA ${ }^{2}$ \\ ${ }^{I}$ Research Scholar, Amity Institute of Education, Amity University Uttar Pradesh, India \\ ${ }^{2}$ Associate Professor, Amity Institute of Education, Amity University Uttar Pradesh, India
}

\begin{abstract}
The world hasn't seen a pandemic caused by the Covid-19 virus in a century and this has caused severe disruptions of the day to day normal life in all spheres of the society. Since it has impacted everyone, this paper has been written to focus on the transformations it has caused in the education sector which has impacted the entire student and the teacher community. Though the internet revolution in the country has been gaining momentum from the past many years, this pandemic has brought it on major focus and it has gained maximum momentum. There has been a complete shift in the way education goals are being delivered and both the teaching and the student community has to gear up for the new normal. As the world is grappling up and coming to terms with this pandemic and devising ways to minimise the impact, many new innovations in the field of technology is aiding this momentum. The educational sector is bracing up and adjusting with these new situations like never before and trying its best to overcome the situation.

KEYWORDS: Online Education, Transformation in Education System, E-Learning
\end{abstract}

Received: May 27, 2020; Accepted: Jun 18, 2020; Published: Jun 30, 2020; Paper Id.: IJMPERDJUN2020210

\section{INTRODUCTION}

The pandemic of the century Covid-19 which started in last quarter of 2019 coming out of Wuhan China has unfolded as an unprecedented calamity on the mankind. This has affected all strata of the society, in some way or the other, more so the education sector, which has impacted millions of students across the globe. In India second week of March, calls were taken by the state governments to close down the schools and colleges all across, as a measure to contain the spread of novel corona virus. Post the effects of Covid-19 on the society as a whole, the education sector has taken a severe hit as the physical classes have come to a screeching halt and the student and the teachers are struggling to cope up with the new normal and the pressures of completing the curriculum. It's imperative to gradually shift to the online platforms for imparting quality education and the importance of elearning is paramount now. The Covid 19 pandemic has severely interrupted all the major sectors of the economy all around the world. Never has the world seen a pandemic of such nature in the near past and hence it has caught all of us unawares. The companies and the professionals have switched to the new normal and have adopted to the work from home culture and operating through the video calls to get in touch with the colleague's, and for many it has been a quick transition. In fact many of them have been quoted saying that the overall productivity has increased, as they are not spending time in travelling to and fro to the work places, the current situation has been very challenging for the education sector all over the globe. The severe disruptions in the daily activities of the students and the teachers have made them reimagine and re-invent the overall education system. Many schools and educational institutions are gradually transitioning to the new normal of e-learning and online classes. This shift has not only been done by the private sector institutes but also many government supported institutions have also made 
this shift to the new ways of learning. The global pandemic has been severe all over and has made the educational systems halt abruptly, but on the positive side it is making the learning online and technological advancing of the entire medium of learning.

\section{E LEARNING INITIATIVES}

Learning is going digital and the future is going to be led by these digital innovations and interventions by AI, artificial intelligence. Both e-books and digital coursework are seeing increasing adoption by the student community.

Many schools and educational institutes have started uploading the daily activities on the official intranet with feedbacks from the teachers, which is checked from time to time by the students and the parents. This gives a transparent platform to one and all, where the progress can be monitored. The availability of e-books, online courses and tests, has made the accessibility of these easier to the student community. There is a considerable shift in the mind-sets of the communities to trust these materials and the importance of updated information is supreme. There also has been a considerable demand of content generators which are specialist in the fields, and are updating the course contents at regular intervals. The whole process is very dynamic and has platforms to interact. These courses are getting very popular with the youth which is providing them with new knowledge skill sets. Some of the courses being offered are also in the field of design and art, and many students who could not continue formal education can take advantage of the same and learn new skill sets from the comfort of their homes. Due to the boom in the online digitisation, the education sector has been the biggest gainer. In India the digital boom has paved the path for the e-learning in a big way. But unfortunately in spite of the digitisation wave, and good steps in this like many e-learning websites, laptops etc., and the digital education/e-learning segment becoming mainstream as yet. Why e-commerce players are so keen on education is some of the questions we need to answer as this is the domain of the future. According to India Ratings and Research Pvt. Ltd the e-commerce players want to tap the potential with their customised services and thus the focus on ecommerce. As India has the largest amount of youth population in the world major international companies are targeting and setting base in the country which is giving the much needed boost to the education sector.

E Learning is one of the fastest growing industries and the large players want a share of that pie. Schooling sector can benefit from ecommerce as all items that the students need to purchase for the academic session can all be available on the e-commerce platform, making it very easy for the parents and the students to make the purchases. The items can be straight delivered to the homes comfort at an economical price. However there are very players operating in this domain in the current scenario and lot of work has to be done in this area. The similar format can also be introduced for the university students, who can also purchase books and stationery items from these websites. Many new schemes can be introduced which could benefit the students at large. These could be making the payments through easy to pay Emi's which will be beneficial to the students who mostly are studying on educational loans. Courses which need lots of art supplies and stationary items such as the design courses need to also introduce the system of value packs, where the students can buy the materials in bulk and also save lots of money. The most important feature to cope up with the Covid-19 pandemic is to make sure that the learning process is not disrupted and is seamless for both the teachers and the student community. It's very important to utilise the various digital methods like video calls, laptops and smart phones to connect the students to the teachers so that the process of learning is not hampered and is conducted in a smooth manner, as it's trying to replicate the physical classrooms and the activities. This is also the best times for the student and the teacher communities to adapt 
to these changes and make the overall education system more productive and efficient, during this unprecedented Pandemic which is grappling the world.

\section{DIGITAL TRANSFORMATION OF EDUCATION SYSTEM}

The current pandemic has fast paced the adoption of new technologies and hence has made the educational institutions, online businesses to work together with each other and find solutions which are easy to adopt and fast paced. Due to this situation many educational institutes are finding this to be the ideal time to invest in new technologies to make the overall educational system more meaningful and overall satisfying the needs. This has ensured that the disruption made due to the pandemic hasn't hampered the overall curriculum goals and hence this digital transformation is the new normal. This has led to a situation where many students are also learning a new skill which is giving them a chance to be more productive. The new technologies have led to a more focussed approach which is leading the transformation from an educator centric education system to a student centric education system. The new norms of online classes are bridging the gap between the teachers and the students and helping them in bringing the same experience as the physical classes, if not full but to some extent. These online classes are designed in such a way that it's fulfilling the needs of the brick and mortar classrooms and also all the interactions between the students and the teachers and also the parent teacher meetings which are happening online. The technology driven classes are also making the overall educational system more transparent and everything is documented and archived in the systems. The overall online education system ensures that there is a fine balance between the teachers, course content, curriculum developers and can be successfully achieved through the availability of the internet connection, computers and laptops. The current situation led by the Covid-19 has ensured that there is a transformation in the education system and it's available for all.

It's very important for the teachers to prepare thoroughly for the classes as compared to the physical classes in a different way. The lesson plans and the sessions need to be meticulously planned as per the subject matter. It's important to keep the session flows interesting so that the engagement levels remain high through the session of the class. Thus a considerable amount of preparation needs to be done before each and every class. Below mentioned flow is prepared to demonstrate the sequence in the flow of these sessions, which needs to be planned by the educators

\section{PREPARING FOR THE CLASSES}

\section{Create Session Plans}

- What will be covered during each session - Topics of the subject to be taught.

- What goes in the topic (content readiness) for the subject concerned.

- Flow of the session needs to be planned well in advance.

- Engagement activities around the subject and how the teacher would assess.

- What needs to be checked with students \& when for the assignments.

- References / Student kit for students / self for the session planned.

- Create Communication for students about the class -details \& time - Calendar invite \& message with 15 minutes heads up reminder. 
- Prepare and share Pre Read materials for students, Prepare Student management sheet for the sessions for attendance.

\section{What Students Need to Receive?}

- $\quad$ Time slot / calendar invites for the class in advance.

- $\quad$ Subject name / teacher name / context \& reading material(pre)

- What is required during the class, in terms of activity and flow of the session.

- $\quad$ Link details for the session.

\section{DURING THE SESSION}

- $\quad$ Provide a student's kit to the students in the class.

- Focus only on key elements in class (the rest as pre and post reads)

- Maintain on-screen movement, it promotes interaction in the class.

- Use student management sheet to engage students by using their names.

- Do not let one slide be on screen for long - change the slide - switch between mediums for better engagement.

- $\quad$ Thumb rule: 1 slide = 1 point $/ 1$ thought broadly for more impact.

- Ask questions frequently and seek responses from all learners. Do not let only a few learners answer all questions. Call upon the ones not responding.

- Help learners recall prior knowledge by asking questions.

- Responses can be taken by voice (for discussions), or over chat or white board.

- $\quad$ Keeps sharing practical use of topics being covered and plan exercises activities around them.

\section{INTERVENTION OF GOVERNMENT}

The local governments and even private sector enterprises have come up with many new initiatives for the student community to support them in this hour of distress, as the schools and the colleges are closed now, due to the spread of the pandemic. When the lockdown started and there was a complete closure of all enterprises and all the educational institutes including the school and colleges, many measures were taken to support the education system. To aid the student community during this lockdown, the initiative of online learning was undertaken and launched the government like the Swayam, e-pathshala, Diskha and many other portals. This has minimised the impact of the lockdown to a great extent.

Various subject matter experts are giving lectures through webinars which the student community is attending and getting knowledge. These webinars are providing instrumental in bridging the academic industry association and is very fruitful for the student community at large. 


\section{PLAYERS IN E COMMERCE EDUCATION-}

The e commerce landscape in the field of education has been in focus and many private players have been eyeing the same. E commerce players and other social networking sites like Corsera, Udemy and many others are working as a great enabler to bridge the gap between the student communities and the specialized courses. These courses are sought after and linked with skill development, which is linked to employability. Having said that, since it's a new technology which is still evolving stage, there are many challenges in the way of a smooth and seamless running of these programmes all over the globe, and much work is happening in this field by both the private and public sector enterprises. The support to the ecommerce companies which are imparting the online education in all fields by the governments and the institutes will play a very important role for these programmes to be successful. It's the need of the hour that the educationists, academicians, managements of the companies, all come on the same wavelength and work together to find solutions at the global level to aid the current situation. The internet and technological advance's which India has seen in the past one decade has proved instrumental in the field of online education and educational e-commerce. Companies such as Flipkart, Snapdeal and Groupon have entered the field of ecommerce in education in the past few months. Online education is a more than $\$ 5$ billion market and they are always on the "look out for new opportunities". Snap deal has launched online education offerings. Overall, Snapdeal has around 5,000 courses on offer for its over 25 million users. Snap deal aims to earn 20\% of its revenue from service offerings including online education, which will provide the much needed focus and impetus to the sector. Though various players have entered the e commerce business in education and there are several online education content providers but they are fragmented and lack a nationwide distribution network and some players are trying to organise it. This is a great challenge which the e commerce in education has to bridge as India is a big country with multiple socio economic scenario and a huge geographical expanse. The demands of the students vary from region to region and the expectations need to be set to fulfil the demands of the growing student population. The traction will come from the distance education and executive education segments which would bridge the gap between the formal and the informal sections of education. As correspondence courses shift to paper-less format, this will gain momentum in the coming future.

\section{CHALLENGES IN ONLINE EDUCATION}

The online education where it is opening new avenues, also brings lots of challenges with it. The biggest being the change in mid-sets, which has to be channelled in for it to be successful. As many teachers and also students are not used to this change, they are finding it a struggle to adjust to the new norms. Also with the sudden and almost abrupt way the physical classes have been shut, this has come a blot out of the blue. Apart from the common challenges of hardware's being not present with all students, and the net speed specially in the far flung areas is a real challenge, which is hampering the speed of these virtual classes. Many students and teachers are struggling with the frequent disruptions in these classes, which can be very frustrating due to lower bandwidths, especially in the remote areas. Maintaining the concentration levels for the entire class is also a challenge which the students are facing. Lack of a physical transaction is also making it less interactive and due to this many students are not able to concentrate in the ongoing classes. In India the overall internet penetration is only 35 percent with very limited internet speeds, it's become very challenging to deliver the online classes due to the major shift from the offline to online classes and delivery of the classes due to the pandemic. With all the schools and colleges being closed for such a long time, it's become very challenging for these institutes to deliver the education goals and maintain the day to day activities. While these have not been too much of a problem in the major 
metros, where the infrastructure is good and the awareness of online is also high, it's been quite a challenge for the smaller towns and the far flung areas. The remoteness of the place is providing to be a hindrance in the smooth running of classes. Also it has been seen that the students from lesser economic backgrounds don't have the necessary computers, laptops and also reliable network connections which is leading to absence in these classes for these students which is a big challenge to overcome. So the result is that the overall experiences of the students in the metros have been way ahead than the students on the far flung smaller towns of the country which is not a surprise. It has also been seen that the students are also not very serious about these online classes, many are skipping, not waking up on time, and this is resulting in a huge challenge for the teachers to complete the curriculum on time. As crucial time is being lost, it's very crucial for the classes to run on time to complete the stipulated curriculums. Students should also be given study material links after the classes for selfstudy which is very important, which will give additional information on the topic, which is being taught. Teachers should be better prepared and it's very important to send the students the study materials. Thus the active engagement of the teachers with the individual students is very crucial and overseeing the assignments and giving feedback is very crucial. Without this engagement the overall effect of the education imparted will lose its effect. Students need to be engaged and hence the overall mechanism and the content also need to be tweaked for the same to get the desirable results. It's imperative that the classes are made very engaging through visual medium and giving examples which are relevant to the topic. It's important that these classes are not very long, as the students will lose interest and will not be able to attend till the end of the class, and will then miss out on some important topics. The human interaction which happens in the physical classrooms can never be matched with the online classes, where the class is far from each other; hence the role of the teacher also becomes very important so that the motivational levels of the students are also kept intact. It's very important for the entire class to be engaged by various mechanism, and these can be a quiz, some interesting assignments.

\section{WAY AHEAD AND THE FUTURE}

Students can really take the benefits of these schemes whenever they are announced. This would not only save money but would also allow them to save precious time which they can utilise in their studies. Lot of work needs to be done in this regard as not many big ecommerce players are very keen on this and are more happy earning profits by selling commercial items. Education sector really needs to collaborate with the ecommerce players to get the desired results as digital is the only future. Academic institutions like the schools, colleges and the universities need to actively participate not only in the ecommerce of educational products but also launching online programmes which will be beneficial for the student's community at large. Skill development is key to the development of the society at large providing employability which is very crucial. It will take academics to every home, widening the learning opportunities for kids and making them accessible to one and all.Edu-commerce will further empower the parents to ensure that only the best products for their kids' education are bought in the most economical manner. There is lot of work which needs to be done in the field of e commerce in education and the challenges have to be overcome to get the desirable results.

\section{REFERENCES}

1. https://redseer.com/newsletters/ed-tech-market-updates-July18

2. https://www.indiatoday.in/education-today

3. Impact of E-Learning in Education Himanshu Agarwal1 , G. N. Pandey2, International Journal of Science and Research (IJSR), Volume 2 Issue 12, December 2013 
4. Education Reform of E-commerce Based on the Concept of "Innovation, Creativity and Entrepreneurship", Shengbo Shi, International Conference on Education Reform and Modern Management (ERMM 2014), Institute of Information Technology, Zhejiang Shuren University

5. The Positive Impact of eLearning-UPDATE, UNESCO, white paper on education transformation, 2012 by Intel

6. The Positive and Negative Impact of Social Media on "Education, Teenagers, Business and Society, International Journal of Innovative Research in Science, Engineering and Technology, Vol. 6, Issue 10, October 2017, Harshit Lad

7. Patel, Hardik, Adarsh Patel, and Prashant Shah. "Impact of e-learning in the development of student life." IMPACT: International Journal of Research in Engineering \& Technology (IMPACT: IJRET) 2.4 (2014): 235-238.

8. Ghorbani, Maryam., Fateme Noori Sarukolaee, and Madh. Dast-Mard. "The use of participatory learning method in training higher levels of learning in e-learning system." IMPACT: International Journal of Research in Humanities, Arts and Literature (IMPACT: IJRHAL) 2.7 (2014): 1-8.

9. Banerjee, Soumendu., and Sunil. Karforma. "Object oriented metric based analysis of space efficient LSB based steganography including compression for securing transmission of e-learning documents." International journal of mechanical and production engineering research and development (IJMPERD) 7.3 (2017): 11-18.

10. Mudassir Khan, Mohd Ayyoob. "The scope of E-learning in the computer science \& technologies." International Journal of Computer Science Engineering and Information Technology Research (IJCSEITR) 6.6 (2016): 1-6.

11. George, aspridis., et al. "Assessment of e-Learning Methods in Public Administration. The Case of the Greek National School of Public Administration and Local Government." International Journal of Human Resource Management and Research (IJHRMR) 3.5 (2013): 19-36.

12. Bhuvaneswari, S. Srivara Buddhi, and A. Dharanipriya. "Attitude of UG Students towards E-Learning." International Journal of Humanities and Social Sciences (IJHSS) 9.2 (2020):35-40 

